\title{
Libros y editores. Las primeras empresas editoriales en el México independiente. 1830-1855
}

Laura Suárez de la Torre INSTITUTO MORA

\begin{abstract}
Este ensayo expone el proyecto Editores-Empresarios en la Ciudad de México. 1830-1855, cuyo objetivo principal es rescatar a los personajes que encabezaron el panorama editorial mexicano de las primeras décadas de vida independiente.
\end{abstract}

Personaje comprometido generalmente con las ideas que imprime, promotor de periódicos y revistas, diputado a veces, miliciano nacional otras, guiado[ [...] por la máxima francesa: los libros gobiernan al mundo; de aquí el distinguido ejercicio del noble arte de la imprenta y de los libreros editores. ${ }^{1}$

$\mathrm{E}$ I texto aquí publicado se presentó en el marco del coloquio Prestigio, Riqueza y Poder. Las Elites en México (1821-1940), en la

${ }^{1}$ Villacorta, Burguesia, 1980, p. 35. sesión Elites Culturales. ${ }^{2}$ Este trabajo recoge algunos de los planteamientos del proyecto CONACYT titulado Editores-Empresarios en la Ciudad de México. 1830-1855, iniciado recientemente en el Instituto de Investigaciones Dr. José María Luis Mora. De esta manera, en las páginas siguientes se encontrarán una serie de hipótesis en torno a nuestro tema de investigación, resultado del seminario mensual, en el que participamos investigadores del Instituto de Investigaciones Dr. José Ma-

\footnotetext{
${ }^{2}$ La ponencia fue revisada y modificada para su publicación.
} 
ría Luis Mora, la Universidad Nacional Autónoma de México y la Universidad Autónoma Metropolitana. ${ }^{3}$

Para exponer nuestra investigación, se decidió dividir el presente texto en cuatro puntos. A saber, el estado de la cuestión; el proyecto Editores-Empresarios en la Ciudad de México. 18301855; los temas de nuestra investigación, y Consideraciones finales.

\section{EL ESTADO DE LA CUESTIÓN}

La historiografía de la primera mitad del siglo XIX se ha abocado, primordialmente, al estudio del acontecer político en un afán por encontrar las bases de la formación del Estado mexicano. Este hecho ha dado como resultado un cuantioso número de trabajos dedicados a este tema, privilegiando diferentes aspectos. ${ }^{4}$ Sin embargo, esta tendencia por el quehacer político ha dejado de lado cuestiones fundamentales en la problemática de esa etapa. La sociedad, la cultura y, en menor grado, la economía, han quedado relegadas del interés de los historiadores como si constituyeran un mundo separado del político, cuya presencia no fuera relevante en el acaecer cotidiano de los mexicanos. La historia cultural ha sido uno de los temas menos tratados por los historiadores mexicanos, a pesar de

\footnotetext{
${ }^{3}$ Lilia Guiot de la Garza, Ma. Esther Pérez Salas, Laura Solares Robles y Laura Suárez de la Torre, coordinadora del proyecto, del Instituto Mora; Miguel Ángel Castro y Antonia Pi-Suñer de la UNAM, y Javier Rodríguez Piña de la UAM.

${ }^{4} \mathrm{La}$ vida política nacional constituye el tema más recurrente dentro de la historiografia mexicana y extranjera dedicada a nuestro país.
}

que las nuevas tendencias historiográficas se interesan por ese estudio. ${ }^{5}$

En ese sentido habría que decir que la historia cultural mexicana se muestra ante nuestros ojos como una rica veta $a$ indagar y que podemos abordar desde muy diversos ángulos. El México del siglo XIX ofrece en este ámbito un campo casi inexplorado de investigación. Precisamente por ser una temática novedosa, con grandes posibilidades, se decidió enfrentarla a partir de la actuación y los intereses de quienes se ocuparon de imprimir y difundir la literatura, en su más amplio sentido, y

${ }^{5}$ Diversos autores europeos han realizado trabajos en este sentido, destacándose la labor emprendida por los historiadores franceses en cuanto al rescate de la importancia del libro en la vida de los pueblos. Como ejemplos podemos citar: Hauser, "Revistas", 1969; Jitrik, Lectura, 1987; Hell, Idea, 1986; Kahn, Concepto, 1975; Labarre, Livre, 1971; Martin, Livre, 1969; Martin y Chartier, Livre, 1982; Quéniart, Culture, 1978; Scheler, Hombre, 1947; Villacorta, Burguesia, 1980, p. 35. Autores como José Luis Martínez, María del Carmen Ruiz Castañeda, Pilar Gonzalbo o Alicia Perales Ojeda han escrito obras monográficas en torno al caso mexicano. Otros, en diversas épocas, han redactado pequeñas obras reseñando aspectos diferentes de la cultura nacional y se han acercado a la labor de los diversos impresores, Jaime Avilés, Salvador Azuela, José Bravo Ugarte, Enrique Fernández Ledesma, Jesús Galindo y Villa, Andrés Henestrosa, Juan Bautista Iguíniz, Maria del Carmen Reyna, Eloísa Uribe y Ernesto de la Torre Villar, han sido, entre otros, los encargados de esa empresa. Algunos trabajos como los coordinados por Lilia Granillo recientemente, recogen en una sola obra diversos ensayos sobre diferentes enfoques de la cultura. Ver Granillo, Identidades, 1993 y Más, 1994. Asimismo hay que señalar el trabajo que últimamente publicó el Colegio de Jalisco en torno a la labor de los editores catalanes en México: Ferriz, Edicion, 1998. 


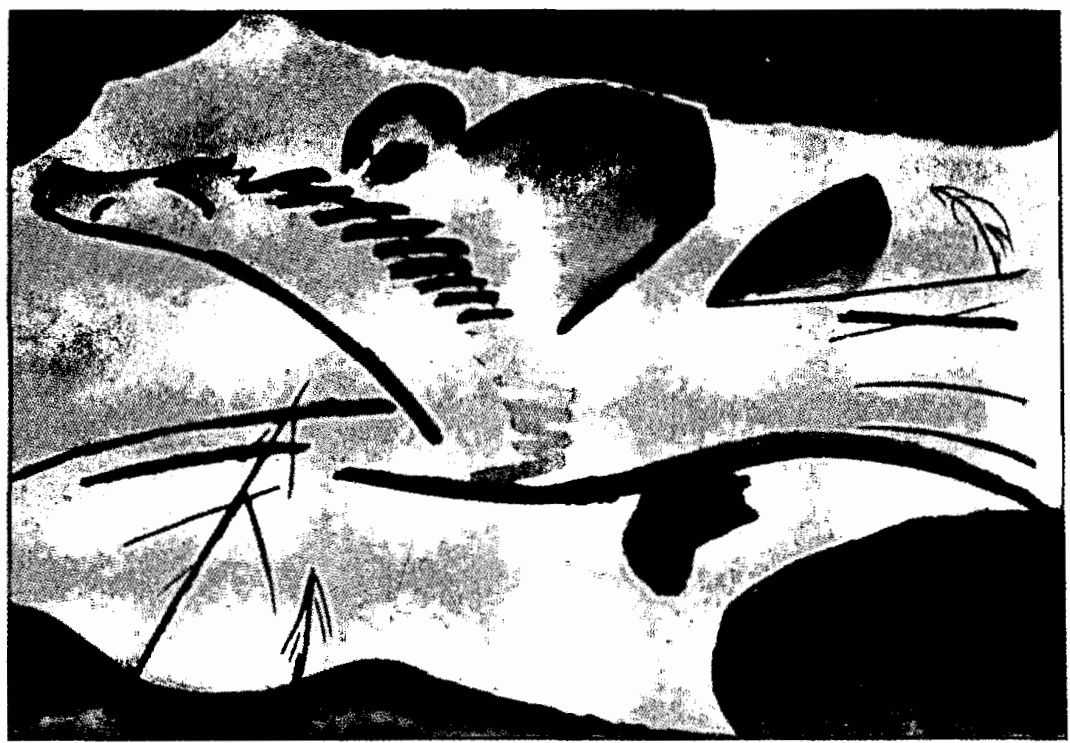

de reflejar a través de su actividad cotidiana un aspecto de la vida cultural del México de la primera mitad del siglo XIX. Así, a partir del estudio de las librerías y los editores, nos acercaremos a una faceta de la historia cultural mexicana.

EL PROYECTO EDITORES-EMPRESARIOS EN la CIUdAd de MÉXICO. 1830-1855

El proyecto Editores-Empresarios en la Ciudad de México. 1830-1855 se concibió con un objetivo fundamental: intentar un acercamiento a la vida cultural a través de la identificación y la labor de quienes encabezaron las tareas editoriales, y destacar el papel de las principales librerías que expendieron el saber durante las primeras décadas de vida independiente.

Si bien el tema ha sido objeto de estudio de algunos escritores, la mayoría de los textos en torno a la labor tipográfica únicamente nos ofrece pequeñas biografías de quienes se constituyeron en los impresores más sobresalientes de ese entonces, o bien de los autores que enfrentan la temática desde otra perspectiva: a partir de la reproducción de facsímiles de las publicaciones más representativas. ${ }^{6}$ Habría que

${ }^{6}$ Cabe destacar la labor emprendida por el Instituto de Investigaciones Bibliográficas de la UNAM que se ha destacado por rescatar y poner en manos del público una cuidada selección de obras del siglo XIX. 
precisar que el trabajo novedoso que desarrollaremos no únicamente se acercará a la vida y las obras de quienes se constituyeron en la elite impresora, sino que buscará aportar otras líneas de investigación que permitan ofrecer un panorama más completo de la vida editorial $y$, por ende, cultural durante el periodo 1830-1855, y de reconocer en todo este quehacer los intereses de quienes publicaban, promovían y adquirían la letra impresa.

De esta manera, se busca rescatar la vida de los impresores, al igual que descubrir sus ligas políticas, sus filiaciones ideológicas, sus intereses culturales y comerciales; asimismo se aspira a otorgar una dimensión real a los centros promotores de la lectura, es decir, las librerías y los gabinetes de lectura. Este análisis permitirá conocer la importancia que alcanzaron los impresores en un México que comenzaba a despojarse de sus viejas ataduras coloniales, pues como bien señala Francisco Villacorta, "una nueva clase dominante, una sociedad en trance de transformación, exigen otra cultura" $y$, en ese afán renovador, los responsables de las publicaciones cobraron importancia, pues coadyuvaron a difundir los diversos campos del saber en un país ávido de cambios y sumergido en proyectos a realizar.

En ese sentido, valdría la pena señalar que la vida independiente abrió nuevos horizontes a quienes desempenaban un papel dentro del quehacer cultural, pues los impresos, parte importante de la cultura diaria, se multiplicaron, y los títulos de periódicos,

${ }^{7}$ Villacorta, Burguesía, 1980, p. 38. revistas, folletos y calendarios encontraron cabida en el panorama nacional, sin dejar de lado las tradicionales oraciones, novenas, vidas de santos, sermones, cartas pastorales, etc. No obstante el crecimiento de la producción impresa en esos años, los estudios respecto del número de lectores nos muestran que no creció en igual proporción, ya que saber leer y escribir estaba reservado a unos cuantos privilegiados, quienes sin proponérselo, pero gracias a sus demandas culturales, coadyuvaron a promover la actividad editorial a lo largo y ancho del país.

Es preciso señalar también que los responsables de estas empresas eran mexicanos comprometidos con un proyecto de nación, dentro del cual la tipografía cobraría un sitio especial, pues las intenciones políticas y culturales encontraron en la letra impresa un medio para manifestarse. No hay que olvidar que la vida independiente abrió nuevos horizontes, en donde los impresos tuvieron una influencia decisiva; el ansioso grupo criollo aprovechó las circunstancias para convertirse en el nuevo dirigente nacional, "ocupó posiciones preeminentes dentro de la estructura política de la flamante nación y ejerció su predominio en la toma de decisiones que afectaron a la sociedad en su conjunto" 8 , en esta nueva realidad, la prensa tendría un papel protagónico, pues a través de ella se lidiaron las batallas ideológicas, se propusieron los proyectos nacionales y se manifestaron las aspiraciones culturales.

\footnotetext{
${ }^{8}$ Pérez Salas, "Revistas".
} 
A medida que avanzamos en la investigación, encontramos que la imprenta comenzó un desarrollo vertiginoso a partir de 1821, dado que las circunstancias del país la llevaron a ser auspiciada tanto por el gobierno como por los particulares. ${ }^{9}$ En ese delirio de la "libertad", la prensa política alcanzó un gran esplendor y las publicaciones periódicas se multiplicaron; ${ }^{10}$ se pensó que en la letra impresa podría encontrarse la felicidad de la nación al ofrecerle los mejores modelos para encaminarse. Sin embargo, con el tiempo, las páginas impresas no únicamente reprodujeron los debates políticos, sino que cedieron mayores espacios a las aspiraciones de una pequeña elite interesada en dar a conocer las novedades científico-literarias de aquel momento. ${ }^{11}$ Un primer acercamiento al

${ }^{9}$ Ver como ejemplo Ruiz, "Prensa", 1980.

${ }^{10}$ La Abispa de Chilpancingo (1821-1822), El Sol, (1821-1822), Semanario Politico y Literario (1821), El Hombre Libre (1823), Diario Liberal de México (1823), El Águila Mexicana (1823), Gaceta del Supremo Gobierno de la Federación (1823-1827), El Correo de la Federación (1826-1829) El Observador de la República Mexicana (1827), pueden ejemplificar lo arriba dicho, pues en ellas colaboraron clérigos, médicos, militares o abogados más comprometidos con la vida política y cultural que con sus profesiones.

${ }^{11}$ El Diario de México fue el órgano de difusión que inicialmente cedió espacios a los noveles literatos mexicanos durante los primeros años del siglo Xrx. Es necesario señalar también que junto con las inquietudes políticas y científco-literarias, la prensa religiosa continuó teniendo un sitio especial en la vida de los mexicanos, incluso después de la década de los años veinte. El artículo de Suárez de la Torre, "Devoción" 1997, pp. 61-72, puede ejemplificar esa situación. tema nos ha revelado esta situación. Preciso es decir que del análisis que acometamos de las publicaciones y de las empresas editoriales y de la revisión de documentos de archivo se desprenderán otros asuntos que reflejen, por ejemplo, las ambiciones económicas de quienes se encontraban detrás de las empresas editoriales y que expliquen la multiplicación de los establecimientos dedicados a imprimir y a expender el saber y el arte. ${ }^{12}$

La amplia literatura de aquellas décadas nos muestra una realidad: la ruptura del monopolio religioso, auspiciada por los intereses de los editores y por quienes querían ofrecer otras opciones de conocimiento, amparados en la libertad de imprenta que se instauró con el advenimiento de la vida independiente $\mathrm{e}$ influidos por las nuevas corrientes ideológicas surgidas allende las fronteras mexicanas. ${ }^{13}$ En tinta y papel se podían expresar las tendencias políticas, los preceptos religiosos, las aspiraciones económicas, los avances científicos, los debates filosóficos, la historia de otras naciones, las modas literarias, las corrientes artísticas, etc. De esta manera, encontramos que las imprentas de las principales ciudades in-

\footnotetext{
${ }^{12}$ Ver en este artículo la nota referente al número de imprentas.

${ }^{13}$ Desde 1822, el gobierno había decidido que una de las vías del progreso era la libertad de imprenta para "el fomento y propagación de las luces" y promoción de "conocimientos útiles" para "disipar las tinieblas de la ignorancia". En este sentido la instrucción pública cobraba una gran importancia y, al mismo tiempo, se incitaba al desarrollo de las imprentas que no tardaron en hacerse presentes en la capital del país. Ver Rodríguez, "Ciencia", 1992, p. 143.
} 
crementaron y diversificaron su labor: periódicos, revistas literarias, folletos y hojas sueltas, manuales y memorias, calendarios, catecismos y novenas, libros y guías de forasteros, manifiestos y discursos, colecciones de leyes y decretos fueron cada día más familiares en el ambiente nacional. Ello revela, a primera vista, la necesidad de expresar por escrito los intereses de los gobiernos, las ambiciones culturales de las elites o la presencia cotidiana de la Iglesia, por citar algunos ejemplos.

Las ciudades más importantes -México, Guadalajara, Puebla, Oaxaca y Mérida- podían vanagloriarse de contar no únicamente con imprentas, sino también con librerías y gabinetes de lectura que ponían al alcance del público, como bien señala Lilia Guiot, "las últimas novedades llegadas del extranjero y los textos aún calientes salidos de las prensas nacionales". ${ }^{14}$ Los lectores, escasos, como ya se señaló, pero interesados en la letra impresa, fueron un factor decisivo en la ampliación del mercado tipográfico, pues además de costear las novedosas empresas editoriales, se suscribieron a las diferentes publicaciones impresas en distintos puntos del país. ${ }^{15}$ Así, se recibían de lugares conocidos o recónditos solicitudes de suscripción, de lo que podemos deducir que los trabajos editoriales tenían demanda y los dueños de los talleres, seguramente ga-

\footnotetext{
${ }^{14}$ Guiot, "Librerías".

${ }^{15}$ En este sentido, habría que señalar que las partituras también tuvieron demanda y las librerías se encargaron de ofrecerlas a un púbilco interesado en acrecentar sus conocimientos musicales y en aprovechar las nuevas formas de diversión.
}

nancias. ${ }^{16}$ La investigación podrá aclararnos esta pregunta. Gracias a esa proliferación de impresos, poco a poco se ensanchó el círculo de lectores y, por ende, la apropiación de la cultura se expandió, ${ }^{17}$ aunque creemos que, por los altos índices de analfabetismo y pobreza, siguió reservada a un selecto número de mexicanos. Baste señalar aquí el elevado número de publicaciones periódicas para confirmar lo arriba expresado, aunque también es necesario insistir en que por el alto costo de los libros, la cultura fue propiedad de unos cuantos. ${ }^{18}$

No obstante esa realidad, no se debe perder de vista que dentro del proyecto nacional se estableció la necesidad de instaurar los nuevos planes educativos anhelados por el grupo en el poder tendientes, principalmente, a ofrecer la cultura a sectores más amplios. En el interior de los centros educativos y fuera de ellos, los libros, los gabinetes de lectura y las librerías tuvieron un papel fundamental; en este sentido habría que otorgar a los impresores su desempeño en la vida nacional como sujetos transmisores de la cultura, pues las instituciones que otro-

${ }^{16}$ El número de imprentas puede servir para corroborar el auge editorial. Véase la nota referente a este hecho.

${ }^{17}$ Hauser, "Revistas", 1969.

${ }^{18}$ José María Luis Mora se refirió en México y sus revoluciones al estado de la cuestión y señaló lo siguiente: "La importación frecuente de libros y la manía o moda de tenerlos y estudiarlos es siempre creciente en la república [...] a pesar de la asombrosa importación que se ha hecho de este artículo de comercio y de estar enteramente libre de derecho, ningún efecto se ha mantenido constantemente en tan alto precio." Mora, México, 1987, vol. Iv, p. 74. 
ra se habían destacado en ese ámbito padecían los efectos de una guerra reciente y de un erario agotado. Ese trabajo editorial, encabezado esencialmente por una minoría, habrá que rastrearlo para ver si estaba dirigido a otro pequeño grupo relacionado esencialmente con ella o distinto de ella. Conforme la investigación avance nos ofrecerá nuevas luces.

Ahora bien, cabría preguntarnos, quiénes se encontraban detrás del negocio editorial en la ciudad de México y qué objetivos buscaban. Sus nombres se repiten en los pies de imprenta, una veintena de interesados en dar a luz las diversas publicaciones. Ese pequeño número de impresores, quizá vinculado con los directores políticos o voceros de esa elite o acaso mejor dicho miembros de la misma, habrá que estudiarlo como uno de los factores decisivos en la difusión de las distintas manifestaciones culturales que prevalecieron en las primeras décadas del siglo xxx, pues como bien señala Laura Solares: la labor de los empresarios-editores contribuyó a ilustrar a hombres, mujeres y niños a través de la lectura de textos novedosos, prácticos, políticos, culturales y hasta prohibidos, que circularon por las librerías y gabinetes de lectura que comenzaron a instalarse en las principales ciudades de la nueva república. ${ }^{19}$

${ }^{19}$ Solares, "Mariano". En este sentido Mora refirió lo siguiente: "La afición a la lectura ha dado [la ampliación de conocimientos]. Multitud de romances e historietas difundidas por toda la república y leídas con avidez, no sólo han ennoblecido y dado un carácter de finura a todas las pasiones del corazón mexicano, sino que han propagado innumerables noticias de
Pero volviendo a la pregunta arriba expresada, podríamos afirmar que la máxima cristiana "por sus obras los conoceréis", se adapta, en otro sentido, a esos personajes cuyas obras impresas son su única referencia y, al mismo tiempo, punto de partida para su estudio y para comenzar a desentrañar algunos aspectos de su actividad como empresarios-editores de la ciudad de México, desconocidos hasta este momento. La alta producción de impresos y la diversidad de los mismos revelan la importancia de su labor entre 1830 y 1855, etapa de esplendor por la diversidad de materiales que ofrecieron a un público ávido de novedades y que traspasó los límites de la capital. ${ }^{20}$

Distintos y novedosos proyectos editoriales emprendieron nuestros personajes. Baste señalar aquí algunos ejemplos que llevaron a cabo: $E l$ Mosaico Mexicano (1836-1837), El Museo Mexicano (1837-1843), Presentes Amistosos (1847 y 1851-1852), El Álbum Mexicano (1849), La Ilustración Mexicana (1851-1852 y 1854-1855), El Diario de los Niños (1839-1840), El Semanario de las Señoritas (1842), El Espectador de las Señoritas (1842), El Espectador de México (1851-1852) o La Cruz

todos los ramos del saber que se tocan en ellos y excitan la curiosidad de los lectores. El entendimiento, la imaginación, el corazón y el lenguaje se han enriquecido con semejante lectura, aumentándose considerablemente el caudal de ideas, imágenes y sentimientos que forman la base de la civilización y cultura del pueblo mexicano." Mora, México, 1987, vol. rv, p. 101.

${ }^{20} \mathrm{El}$ periodo que delimita nuestra investigación comienza con el desarrollo y diversificación de las publicaciones y culmina cuando se inicia una nueva etapa en la vida nacional, a partir de la caida de la dictadura santannista. 
(1855-1858), ${ }^{21}$ junto con los famosos calendarios que dieron renombre a sus editores y que de tiempo atrás contaban con la demanda del público, se ostentaron como las más ambiciosas empresas de este género que surgieron de manera paralela a la prensa periódica que por esos años ampliaba sus páginas y enriquecía sus títulos. El Fénix de la Libertad, El Federalista Mexicano, El Demócrata, El Indicador de la Federación Mexicana, El Telégrafo, La Lima de Vulcano, La Oposición, El Mosquito Mexicano, El Cosmopolita, La Hesperia, El Siglo $X D X^{22}$ El Estandarte Nacional, ${ }^{23}$ El Monitor Republicano, ${ }^{24}$ La Voz del Pueblo, Diario del Gobierno de la República Mexicana, El Eco del Comercio, El Universal, ${ }^{25}$ El Demócrata, El Constitucional, El Republicano y La Cruz.

De las revistas literarias sólo habría que decir que se hicieron a imitación de los modelos europeos, pero que en ellas, poco a poco se fue gestando una cultura nacional, las primeras traducciones de artículos ingleses y franceses o las copias españolas dejaron espacios para que los mexicanos expresaran sus inquietudes y sentimientos y para conceder que una generación romántica diera rienda suelta a su imaginación, al encontrar en cualquier asunto motivo de inspiración. Surgieron un gran número de poetas y novelistas, científicos e historiadores, los cuales encontraron con sus escritos un

\footnotetext{
${ }^{21}$ Véase Ruiz, Revistas, 1987.

22 Ignacio Cumplido fue el impresor.

${ }^{23}$ Vicente García Torres fue el impresor.

${ }^{24}$ Ibid.

${ }^{25}$ Rafael Rafael fue el impresor.
}

camino virgen que explorar sin grandes obstáculos. José Joaquín Fernández de Lizardi, Guillermo Prieto, el conde de la Cortina, José María Heredia, los hermanos Lacunza, Andrés Quintana Roo, Manuel Eduardo de Gorostiza, José Fernando Ramírez, Carlos María de Bustamante, José Joaquín Pesado, Manuel Payno, por citar algunos nombres, lograron difundir sus escritos gracias al apoyo de personajes como Juan Abadiano, Andrés Boix, Mariano Galván Rivera, Ignacio Cumplido, Vicente García Torres, José Mariano Lara, Manuel Murguía, Juan Navarro, Francisco Ortega, Rafael Rafael o José María Andrade, quienes se convirtieron en promotores de esos noveles literatos, en el sentido amplio de la palabra, interesados en dar a conocer las páginas de su inspiración. ${ }^{26}$ Esa mancuerna escritores-impresores resultó fundamental y en beneficio de una nación que estaba en busca de su identidad. "El editor sustituyó al mecenas; la suscripción constituyó la transición entre ambos", permitiendo el aumento en

${ }^{26}$ Las guías de forasteros son una rica fuente para conocer cuáles eran las imprentas măs importantes de la capital. Escogimos tres años para conocer los nombres de quienes se ostentaban como los principales libreros. En 1842: Juan Abadiano, Ignacio Ávila, Francisco Berrospe, Ignacio Cumplido, José Jimeno, José Mariano Fernández de Lara, Ignacio Lavis, Francisco Ortega, Ignacio Sierra y Rosso, Vicente García Torres, Tomás Uribe y Felipe Yepes; en 1852, Boix y Beserer, Vicente Segura Argüelles, Manuel Murguía, Juan Navarro, José Ma. Andrade, Rafael Rafael y la Voz de la Religión se unian a las antes enumeradas y, en 1854, podían contarse también los talleres de Vicente Cerralde, Santiago Pérez y Manuel Redondas. Véase Galván, Guia, 1842, pp. 160-161; Almonte, Guia, 1852, p. 456, y Galván, Guía, 1854, pp. 318-319. 


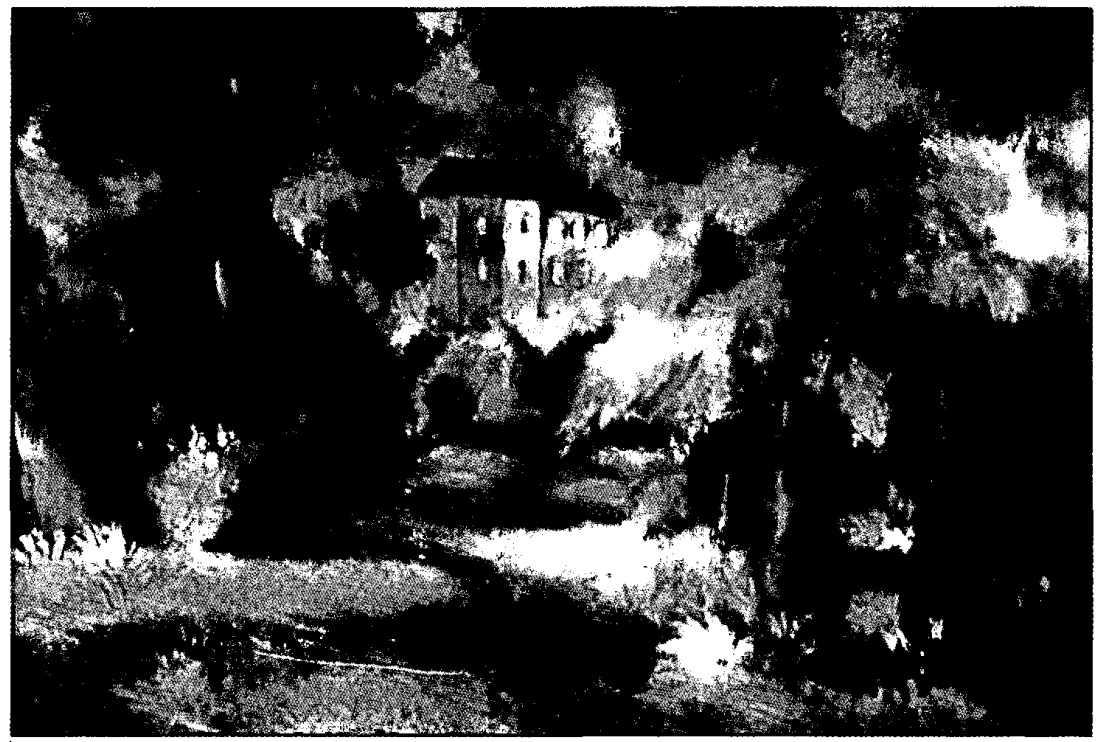

el número de impresos y convirtiéndose éstos en una nueva mercancía con demanda dentro de un sector privilegiado de la sociedad que del periódico pasaría a la lectura de libros y donde la clase media asumirá esa acción. ${ }^{27}$ En este sentido habría que rescatar el valor de las librerías y gabinetes de lectura, como los sitios donde, valga la expresión, se expendió el saber. Asimismo habría que recalcar la variada posibilidad que tuvieron los intelectuales para escoger tal o cual impresor, pues no siempre Carlos María de Bustamante se entendió con Vicen. te García Torres o Lucas Alamán con

\footnotetext{
${ }^{27}$ Hauser, "Revistas", 1969, p. 218.
}

Mariano Galván o José Fernando Ramírez con Ignacio Cumplido. ${ }^{28}$

Antes de pasar a otros aspectos del proyecto, habría que reafirmar la idea de que, en las labores de impresión, sólo unos cuantos fueron los encargados de ofrecer, paralela a la literatura

${ }^{28}$ Baste señalar como ejemplo que Lucas Alamán imprimió sus obras con Mariano Galván, Ignacio Cumplido, José María Andrade, Vicente García Torres y José Mariano Lara. Carlos María de Bustamante lo hizo con Ignacio Cumplido, José Mariano Lara y Vicente García Torres; Guillermo Prieto encontró el respaldo en Ignacio Cumplido y Vicente García Torres; José Joaquín Fernández de Lizardi prefirió a Vicente García Torres, Alejandro Valdés y Mariano Arévalo y el conde de la Cortina se entendió, preferentemente, con Ignacio Cumplido y García Torres. 
cristiana, otrora única opción, una serie de novedades concebidas en México o en el extranjero. En este sentido, tendríamos que ver a estos impresores como a los nuevos detentadores de la cultura y descubrir si actuaron como una minoría propositiva per se, en el concepto moderno de Burzio ${ }^{29} \mathrm{o}$ encauzada por otra, aunque sin desechar los intereses empresariales de cada individuo. También habría que ver si ella cumple, de alguna manera, con la propuesta hecha por Mariano Otero en el sentido de mirar a estos impresores como miembros de una clase media en la que, según el político jaliscien: se, "se hallaban todas las profesiones que elevan la inteligencia", y la que venía a ser "el principal elemento de la sociedad que encontraba en ella el verdadero germen de progreso", 30 constituyéndose así en una elite cultural no necesariamente formada por miembros de una clase superior.

Si bien hablamos de una minoría editora, paradójicamente amplio resultaba el número de impresores en la ciudad de México para una población que oscilaba entre 160 y 200000 habitantes en el periodo al que estamos haciendo referencia y cuya mayoría era analfabeta. Las imprentas y librerias de Ignacio Cumplido, Mariano Galván, José Mariano Lara, Rafael Rafael, Vicente García Torres y José María Andrade, se distinguieron más en el quehacer linotipista por su variada producción o por las novedades tipográficas

\footnotetext{
${ }^{29}$ Burzio afirmó que todo lo original y creativo que se hace en el mundo es obra de minorías. Véase Bobbio, "Elites" en Diccionario, 1995.

${ }^{30}$ Otero, "Importancia", 1972, p. 54.
}

que introdujeron, además de por ser quienes convocaron a la intelectualidad mexicana a las famosas tertulias que tenían lugar en sus establecimientos y a convertirse, de alguna manera, en los voceros "oficiales" de los grupos conservadores y liberales. ${ }^{31}$ Los diversos impresos que salieron de sus prensas reflejan la tendencia ideológica de los propietarios de esos negocios, pues ellos se entendieron mejor con algunos autores y prefirieron imprimir obras que coincidieran con su pensamiento y sus convicciones. El caso de José Mariano Lara es representativo. Precisamente por tener esas características, es que decidimos emprender el rescate de esos impresores y no de otros.

\section{LOS TEMAS DE NUESTRA INVESTIGACIÓN}

En las páginas siguientes se encontrarán algunos ejemplos de las investigaciones que se llevarán a cabo dentro del proyecto Editores Empresarios en la Ciudad de México. 1830-1855. En ellas se podrán ver los diversos linea-

31 Ignacio Cumplido imprimió la famosa carta monárquica de José María Gutiérrez de Estrada, aunque en otros momentos también publicó literatura liberal. José Mariano Lara dio a luz nada menos que la Historia de Méjico de Lucas Alamán; José María Andrade tuvo a su cargo el Diccionario universal de bistoria $y$ de geografia; Rafael Rafael fue el editor del famoso periódico conservador El Tiempo; Mariano Galván fue responsable de publicar los diarios de tendencia liberal El Observador de la República Mexicana y El Indicador de la Federación Mexicana; Vicente García Torres se preocupó por dar a conocer las Leyes de Reforma. 
mientos que han propuesto los investigadores.

Ignacio Cumplido, personaje elegido por María Esther Pérez Salas, destacó como un inquieto empresario interesado en introducir las novedades tecnológicas que el mundo europeo y estadunidense le ofrecieron, y "fue uno de los primeros impresores que incluyó la litografía para ilustrar sus publicaciones, a la vez que empleó prensas de vapor, rotativas y otras máquinas para modernizar su imprenta". ${ }^{32}$ Este hecho revela cuán interesado estaba en renovar el oficio de impresor en México, ofrecer a los grabadores y litógrafos un espacio donde "probar" sus dotes y brindar a su público los modelos artísticos europeos. Además de llevar a cabo sus tareas culturales, participó en la vida política nacional al desempeñarse en cargos como superintendente de cárceles, diputado al Congreso en 1842 y senador dos años más tarde, espacios desde donde intentó poner en práctica sus propuestas de carácter editorial. Con esta investigación se pretende ofrecer una imagen más acabada de Ignacio Cumplido, a quien casi siempre se le vincula con el periódico $E l$ Siglo $X I X$, siendo que su labor editorial trascendió otros ámbitos que lo llevaron a establecer lazos de amistad con la intelectualidad mexicana y, por ende, a ser vocero de quienes detentaban el poder y el conocimiento. ${ }^{33} \mathrm{La}$ investigación destacará la labor emprendida por el editor Cumplido y su carácter

\footnotetext{
${ }^{32}$ Pérez Salas, "Revistas". Ibid.

${ }^{33} \mathrm{La}$ información fue tomada de Pérez Salas.
}

de promotor cultural a través de la publicación de sus revistas literarias y su pertenencia a la elite cultural. ${ }^{34}$

Mariano Galván Rivera, conocido por sus famosos calendarios que a la fecha subsisten, constituye el sujeto de estudio de Laura Solares Robles. En sus primeras indagaciones Solares ha podido demostrar que Galván fue más allá de ser un impresor ordinario, se interesó en los escritos de José Joaquín Fernández de Lizardi, publicó la primera edición mexicana de la Biblia, imprimió el Quijote de Cervantes, de sus prensas salieron los periódicos $E l$ Observador de la República Mexicana y El Indicador de la Federación Mexicana, dirigidos por José María Luis Mora; gracias a su labor, la Historia universal del conde Segur vio la luz en español, etc. También ha podido investigar que, a pesar de los problemas económicos en que se vio envuelto, luchó por mantener su imprenta. Su labor editorial fue intensa y, paralela a ella, supo convocar a los intelectuales a las tertulias que organizó. Personajes como Guillermo Prieto, José Bernardo Couto, el doctor Quintero y Manuel Pesado y Gastañeta le brindaron su amistad y, cuando tuvo lugar el imperio de Maximiliano, se manifestó a favor de él y se vinculó a la Asamblea de Notables, lo que lo llevaría a la postre a prisión, una vez triunfante el ala libe-

${ }^{34}$ Cabe destacar aquí la diferencia entre quienes promovieron la cultura en el México decimonónico a partir de sus propias obras, como Manuel Payno, Guillermo Prieto o Ignacio Manuel Altamirano, y el caso de Ignacio Cumplido, quien desde su taller de impresor se preocupó por la difusión de la cultura. 
ral. ${ }^{35}$ Múltiples son, pues, las vertientes que ofrece la actuación de este personaje, que Laura Solares se abocará a estudiar.

José Mariano Lara, aprendió el oficio en la imprenta de Mariano Galván. Con el tiempo tuvo la oportunidad de establecer su propia tipografía, en donde trabajó a lo largo de muchos años; "enriqueció nuestra literatura con un sinnúmero de folletos y de libros de los que apenas [se han] podido conocer 283 , porque el archivo de esta imprenta no existe, se vendió por papel viejo". ${ }^{36}$ Lara representa al impresor que, al vincularse al poder político, logró publicar una serie de documentos gubernamentales que le causaron incluso una crítica severa. El tratado de paz entre México y Estados Unidos es el ejemplo más representativo. Precisamente por el desconocimiento que existe en torno a su figura, persiste la idea de separar la labor emprendida por José Mariano Lara y José Mariano Fernández de Lara; nuestras primeras indagaciones parecen conducirnos, sin embargo, a conjugar ambos nombres en una sola empresa editorial ubicada en la calle de La Palma, número 4. A pesar de sus amplias tareas en el mundo de los libros, su vida y su obra no han sido investigadas, por lo que me ocuparé de reseñarlas entre 1830 y 1855 , periodo establecido para el proyecto.

Rafael Rafael será tema de otra investigación. Javier Rodríguez Piña se encargará de reseñar la vida y obra de

\footnotetext{
${ }^{35} \mathrm{La}$ información fue tomada de Solares, "Mariano".

${ }^{36}$ Andrade, "Antigua", 1907, t. II, p. 193.
}

este catalán que supo integrarse al mundo cultural mexicano, a pesar de su corta estancia en nuestro país (18441855). Su labor representa la de un editor comprometido con las tendencias políticas ligadas al conservadurismo. Se estrenó en los quehaceres editoriales en 1846, con el periódico $E l$ Católico. Periódico Político, Cristiano, Científico y Literario y, a partir de ese momento, se convirtió en uno de los principales editores de los grupos conservadores. Su nombre también se vincula a la empresa periodística de $E l$ Universal, encabezada por Lucas Alamán, y, como consecuencia de ello, a colaborar en la fundación del Partido Conservador. Sus vínculos políticos derivados de su labor editorial le permitieron incluso llegar a ser cónsul mexicano en la ciudad de Nueva Orleans. Desentrañar las diversas ligas políticas de Rafael Rafael y su labor editorial como impresor y litógrafo, permitirá conocer los distintos papeles que este singular personaje desempeñó en el ambiente nacional a lo largo de sus once años de permanencia en nuestro país. ${ }^{37}$

Una figura que no ha sido estudiada en su justa dimensión es la de José María Andrade, cuyo negocio editorial estaba ubicado en el Portal de los Agustinos, número 3. Su actuación en ese ámbito comenzó al mediar el siglo, como socio de Felipe Escalante, con la publicación del semanario $\mathrm{La} \mathrm{Cruz,}$ y se prolongó a lo largo de muchos años. Su nombre se relaciona con el Diccionario universal de bistoria y de

\footnotetext{
${ }^{37} \mathrm{La}$ información fue tomada de Rodríguez, "Rafael".
} 
geografía, cuyos primeros volúmenes se imprimieron en las prensas de Rafael Rafael, con la Gramática de la lengua castellana según abora se babla..., de Vicente Salvá y Pérez o con la obra titulada El emperador Napoleón III y la Inglaterra que salió de los talleres de Andrade en 1858. De él dijo Felipe Teixidor que fue uno de los editores, libreros y bibliófilos más famosos de México. A pesar de su labor, muy pocos son los datos que nos permiten acercanos a don José María. Responder a las múltiples interrogantes en torno a su vida y a sus tareas en el mundo de la letra impresa, motivó a Miguel Ángel Castro a emprender una investigación con el objeto de rescatar a tan singular impresor. ${ }^{38}$

Vicente García Torres será sujeto de una tesis de licenciatura que llevará a cabo Othón Nava Martínez, becario del proyecto. A la par que ayuda en las tareas de investigación, elabora la biografía y el análisis de las publicaciones que mayor renombre dieron a García Torres, quien se vinculó al trabajo editorial, primero como traductor y luego sacando el tercer tomo de $E l$ Diario de los Niños, primera revista dedicada a la niñez mexicana y, posteriormente, El Apuntador, pionera en cuestiones teatrales. Su labor editorial fue ardua y varios de los más afamados periódicos de la capital estuvieron bajo su dirección: El Monitor Constitucional y $E l$ Monitor Republicano sirven para corroborar lo dicho. Su labor editorial no la interrumpió pese a la presencia estadunidense en la capital del país;

\footnotetext{
${ }^{38}$ La información fue tomada de Castro, "José".
}

mantuvo abierta su imprenta, su periódico no se suspendió e incluso imprimió El nuevo Bernal Díaz del Castillo, de Carlos María de Bustamante. Su interés por publicar lo llevó a empresas novedosas, su mejor ejemplo es la Biblioteca Mexicana Popular Económica, en seis volúmenes, destinada a difundir las obras clásicas del teatro español y a "divulgar artículos de todos los conocimientos existentes desde política y ciencia hasta amenidades". 39 Intelectuales como Manuel Orozco y Berra o Guillermo Prieto entregaron sus escritos a García Torres para su impresión. ${ }^{40}$ Othón Nava analizará tres de sus principales publicaciones y ofrecerá información nueva en torno a su vida.

Hasta aquí hemos mencionado algunos aspectos de varios de los impresores que se investigarán y que reflejan distintos ámbitos de su labor editorial, labor que los llevó también a vincularse con los principales intelectuales de su tiempo, a comprometerse con los acontecimientos políticos de su época y a ser reconocidos como un selecto grupo del que dependió el conocimiento. Si bien los impresores representan una vertiente de lo cultural, ésta no quedaría completa si no nos asomáramos a las librerías y a los gabinetes de lectura desprendidos de la propia labor editorial. La investigación que ha comenzado Lilia Guiot nos brindará la posibilidad de acercarnos a quie-

\footnotetext{
${ }^{39}$ La información fue tomada de Nava, "Vicente"

${ }^{40}$ De Orozco y Berra publicó, entre otros, la cuarta serie de los Documentos, 1856; Prieto, Viajes, 1857.
} 
nes, valga decirlo, negociaban con el conocimiento y de quienes dependía, de alguna manera, el acceder a otras realidades gracias a los libros, periódi$\cos$, folletos y revistas que ofrecían en sus librerías y gabinetes de lectura. Esta investigación ha arrojado una serie de interrogantes: ¿Formaban parte los libreros y dueños de gabinetes de la elite cultural del país?, ¿quiénes eran?, ¿desempeñaban alguna otra actividad relacionada con la difusión cultural?, ¿cuáles eran sus lazos con la elite política?, ¿en dónde se ubicaban sus establecimientos?, ¿cómo eran éstos? ¿qué textos vendían? Si bien son múltiples las preguntas, algunas comienzan a encontrar una respuesta, aunque queda un largo camino por recorrer. ${ }^{41}$

\section{CONSIDERACIONES FINALES}

Tras haber expuesto este proyecto a grandes rasgos y expresado algunas de las líneas de investigación que emprenderemos, nos encontramos con las múltiples preguntas que surgen en torno a estos impresores y a las librerías que muchos de ellos encabezaron. Por principio habría que plantear si ellos se estrenaron en el quehacer tipográfico junto con la nación, o de tiempo atrás venían ejerciendo el oficio. Asimismo habrá que saber si, en realidad, constituyeron una minoría separada de la que condujo las riendas del nuevo país y si formaron parte de los proyectos educativos que encabezó el grupo selecto de mexicanos que, a

${ }^{41} \mathrm{La}$ información fue tomada de Guiot, "Librerías". fin de cuentas, constituía parte de la elite cultural de México. También habrá que ver si figuraron como la intelligenzia encargada de transmitir la cultura en un país que comenzaba a delinear su configuración política o, simplemente, si ejercían la profesión como una actividad comercial redituable. También habrá que ver la relación impresores-artistas para conocer hasta qué punto los editores promovieron el desarrollo de las artes gráficas. Asimismo, nuestra investigación coadyuvará a comprender el mundo de la lectura y de los lectores en un tiempo en que parecían florecer gracias a la actividad emprendida por los impresores. Finalmente, desprendida de esta última realidad, habrá que rastrear la importancia de las librerías y gabinetes de lectura como medios indispensables para propagar el saber y descubrir si quienes se dedicaron a la impresión encontraron también en la venta de impresos un medio para enriquecerse.

En otro ámbito, es necesario destacar la información que empiezan a brindarnos los diferentes repositorios de la ciudad de México. Los archivos guardan documentos vinculados con las imprentas y librerías, sus propietarios, sus deudas y ganancias. Esos materiales nos ayudarán a configurar el mundo empresarial de la letra impresa, tan importante y, al mismo tiempo, tan descuidado por los estudiosos del siglo XIX.

Sin duda que la labor es ardua y que los documentos a los que nos enfrentamos ofrecen materiales de diversa índole; esperamos asimismo que los archivos nos aporten las fuentes de investigación que nos conduzcan a desentrañar 


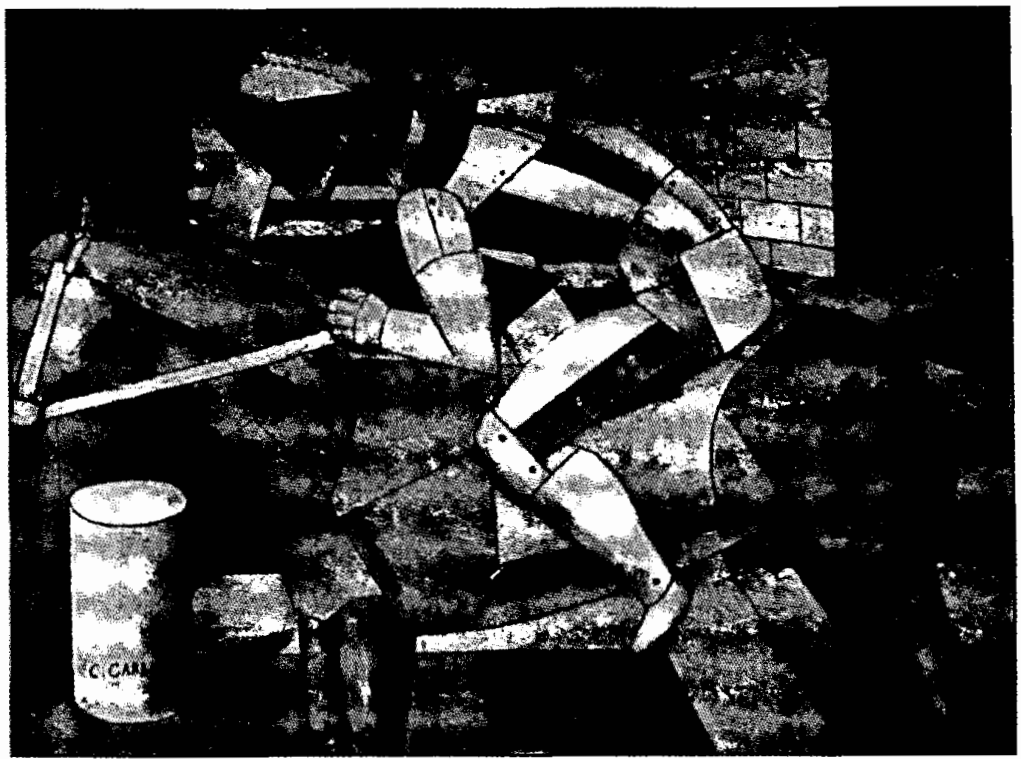

la problemática que nos hemos planteado. Esperamos que esta investigación pueda ofrecer nuevas vertientes a la historiografía mexicana encargada de desentrañar la cultura decimonónica y a reconocer a las elites que descollaron en el siglo XIX mexicano.

\section{BIBLIOGRAFÍA}

-Almonte, Juan Nepomuceno, Guia de forasteros y repertorio de conocimientos útiles, Ignacio Cumplido, México, 1852.

-Andrade, Vicente de, "La antigua imprenta de Lara", Boletín de la Sociedad de Geografía y Estadística de la República Mexicana, Imprenta de Arturo García Cubas Sucesores Hermanos, México, 1907, t. II.
-Bobbio, Norberto et al., Diccionario de politica, Siglo XXI Editores, México, 1995, 2 t.

-Castro, Miguel Ángel, "José María Andrade", inédito.

-Chartier, Roger, Lecturas y lectores en la Francia del Antiguo Régimen, Instituto Mora, México, 1994.

-Ferriz Roure, Teresa, La edición catalana en México, El Colegio de Jalisco/Generalitat de Catalunya/Orfeó Catalá de México, Zapopan, 1998.

-Galván Rivera, Mariano, Guia de forasteros politico comercial de la ciudad de México para el año de 1842.con algunas noticias generales de la república, J. M. Lara, México, 1842.

$$
\text { , Guía de forasteros en la ciu- }
$$
dad de México para el año de 1854, Imprenta de Santiago Pérez, México, 1854. 
-Gonzalbo, Pilar, Historia de la lectura en México, Ediciones El Ermitaño/El Colegio de México, México, 1988.

-Granillo Vázquez, Lilia, Identidades y nacionalismos: una perspectiva interdisciplinaria, UAM-Azcapotzalco, México, 1993.

—, Más de 500 años de cultura en México, UAM-Azcapotzalco, México, 1994.

- Guiot de la Garza, Lilia, "Librerías y gabinetes de lectura en la ciudad de México, 1830-1855", inédito.

-Hauser, Arnold, "Las revistas literarias como instrumento formal para la cultura" en Historia social de la literatura y el arte, Ediciones Guadarrama, Madrid, 1969 (Punto Omega, 20).

-Hell, Víctor, La idea de cultura, FCE, México, 1986.

Jitrik, Noé, Lectura y cultura, UNAM, México, 1987.

-Kahn, J. S., El concepto de cultura. Textos fundamentales, Editorial Anagrama, Barcelona, 1975.

-Labarre, A., Le livre dans la vie amié. nise du XVe siècle. L'enseignement des inventaires après décès 1503-1576, Nauwelaerts, Paris-Lovaina, 1971.

-Martín, J., Livre, pouvoirs et societé à Paris au XVIJe siècle (1598-1701), Droz, Ginebra, 1969.

- y R. Chartier, Le livre conquérant. Du moyen age au mileu du XVIIe siècle, Promodis, París, 1982.

-Mendizábal, Miguel Othón de et al., Ensayos sobre las clases sociales en Mé. xico, Editorial Nuestro Tiempo, México, 1972.

-Mora, José María Luis, Obras completas, Histórica. México y sus revoluciones, Instituto Mora/sEP, México, 1987, vol. Iv.

-Nava Martínez, Othón, "Vicente García Torres", inédito.

-Orozco y Berra, Manuel, Documentos para la bistoria de México, Vicente García Torres, México, 1856.

-Otero, Mariano, "Importancia de las clases medias" en Miguel Othón de Mendi- zábal, Ensayos sobre las clases sociales en México, Editorial Tiempo, México, 1972.

-Pérez Salas Cantú, María Esther, "Las revistas ilustradas en México como medio de difusión de las elites culturales, 18321854" en Graziella Altamirano (coord.), En la cima del poder. Elites mexicanas. 1830 1930, Instituto Mora, México, 1999.

-Prieto, Guillermo, Viajes de orden suprema, Vicente García Torres, México, 1857.

-Quéniart, J., Culture et societés urbaines dans la France de l'ouest au XyJJe siècle, Klincksieck, París, 1978.

-Reyna, María del Carmen, La prensa censurada durante el siglo $X I X$, SEP, México, 1976 (SepSetentas, 255).

-Rodríguez, Leonel, "Ciencia y Estado en México: 1824-1829" en Juan José Saldaña (comp.), Los orígenes de la ciencia nacional, Sociedad Latinoamericana de Historia de las Ciencias y la Tecnología/ Facultad de Filosofia y Letras-UNAM, México, 1992.

-Rodríguez Piña, Javier, "Rafael Rafael y Vilá, el conservadurismo como empresa", inédito.

-Ruiz Castañeda, María del Carmen, "La prensa durante el Primer Imperio y la república federal" en Salvador Novo (coord.), El periodismo en México, 450 años de bistoria, UNAM, México, 1980.

$\longrightarrow$, La prensa, pasado y presente de México, unAM, México, 1987.

- Revistas literarias mexicanas del siglo XIX, UNAM, México, 1987.

-Scheler, Max, Hombre y cultura, SEP, México, 1947.

-Solares Robles, Laura, "Mariano Galván Rivera", inédito.

-Suárez de la Torre, Laura, "De la devoción al interés político", Secuencia, Instituto Mora, núm. 39, sep.-dic. de 1997, pp. 61-72.

Fernández de Lara", inédito.

-Villacorta Baños, Francisco, Burguesia y cultura. Los intelectuales españoles en la sociedad liberal, 1808-1931, Siglo XXI, Madrid, 1980. 